\title{
Self-Medication Patterns Among Medical Students in North India
}

\author{
Mir $^{3 *}$ \\ ${ }^{1}$ Former Medical Officer at Shri Mata Vaishno Devi Shrine Board, India \\ ${ }^{2}$ IMO Grade 1 ESIC Hospital, India \\ ${ }^{3}$ SKIMS Soura, India \\ *Corresponding author: Mohammad Sarwar Mir, SKIMS Soura, India
}

Neelam Kotwal ${ }^{1}$, Sunil Kumar ${ }^{2}$, Monika Malhotra ${ }^{2}$, Saurabh Sadotra ${ }^{2}$, Pankaj Kumar ${ }^{3}$ and Mohammad Sarwar

\begin{abstract}
Introduction: Self-medication results in wastage of resources, increases resistance of pathogens and generally causes serious health hazards such as adverse drug reactions, prolonged suffering and drug dependence.

Method: A cross-sectional descriptive study was conducted. The participants were medical students from first to final year. The data was collected using a questionnaire. The data was analyzed using SPSS version 2.0.

Results: A total of 100 students, 61 (61.00\%) male and 39 (39.00\%) female, were included in the study. Of the medical students surveyed, self-medication was reported among $88 \%$. The most common ailments for which self-medication were used were: the common cold and headache. The students consulted their textbooks and peers for the medications. Antipyretics and analgesics were the most common self- medicated drugs.

Conclusion: The prevalence of self-medication among medical students is high, facilitated by the easy availability of drugs and information from textbooks or seniors. The potential problems of self-medication should be emphasized to the students.
\end{abstract}

Keywords: Self-medication; Medical students; Drugs

\section{Introduction}

Self-medication can be defined as obtaining and consuming drugs without the advice of a physician for diagnosis, prescription or surveillance of treatment [1-3]. Self-medication differs from selfcare in that it involves drugs that may do good or cause harm [4]. It has been found that inappropriate self-medication causes wastage of resources, increases resistance of pathogens and generally causes serious health hazards such as adverse drug reactions, prolonged suffering and drug dependence [4-7].

\section{Material and Methods}

A cross-sectional study was undertaken. The study population consisted of medical students from first to final year, within the age group of 18-25 years. The information pertaining to the pattern of self-medication, indications for self-medication and drugs used for self-medication were included in the questionnaire. The data was analyzed using SPSS version 20.00 .

\section{Results}

A total of 100 students participated in the study, of whom $61(61.00 \%)$ were male and $31(39.00 \%)$ were female. A total of 88 (88.00\%) participants practiced self-medication (Figure 1).

\section{Discussion}

Self-medication is becoming an increasingly important area within healthcare, and this study has shown that it is even more prevalent among medical students. This study has found a prevalence of self-medication of $88 \%$ in medical students in Figure 2 contrast to $59 \%$ in a non-medical population in a previous study 
[2]. It is also noted that a high level of education and professional status are predictive factors for self-medication [4]. This is similar to the findings in a study conducted by Relend Hem and colleagues 6 $(90 \%)$ but is higher than the findings $(60 \%)$ in the study conducted by Henry James and colleagues [4]. In the study it was noticed that the classes of drugs that were commonly used were antipyretics analgesics , antihistamines and antibiotics .This is similar to studies done earlier $[4,5]$. The study has found that self-medication is very common among medical students, facilitated by the easy availability of drugs, and information from textbooks/seniors (Figure 3). Since inappropriate self-medication has the potential to cause serious harm, not only to the students themselves but also to those whom they suggest medication, potential problems of self- medication should be emphasized to the students to minimize this risk.

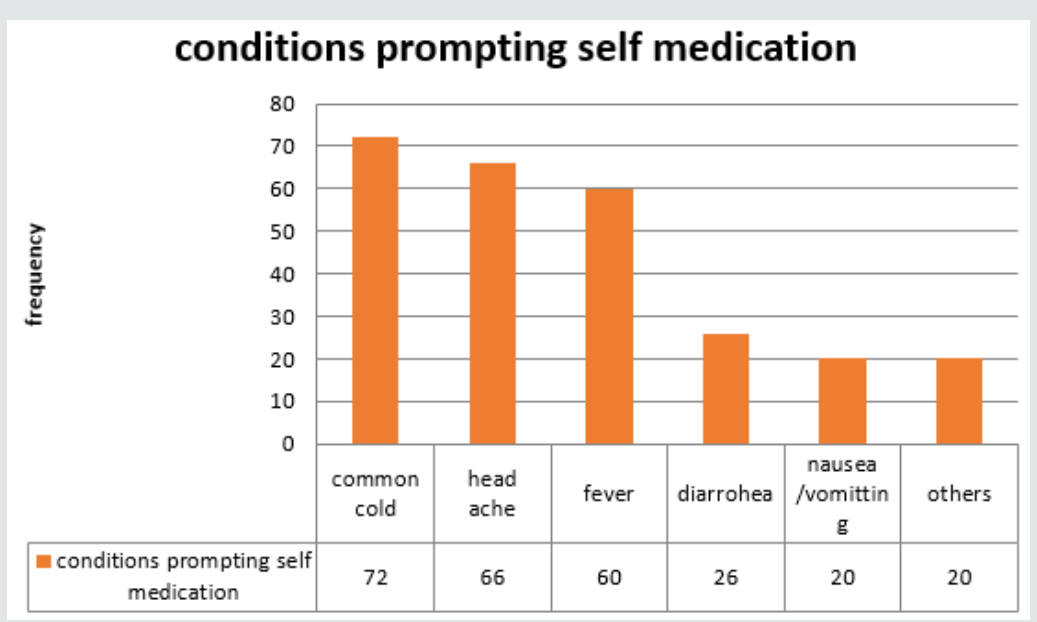

Figure 1: Conditions prompting self-medication.

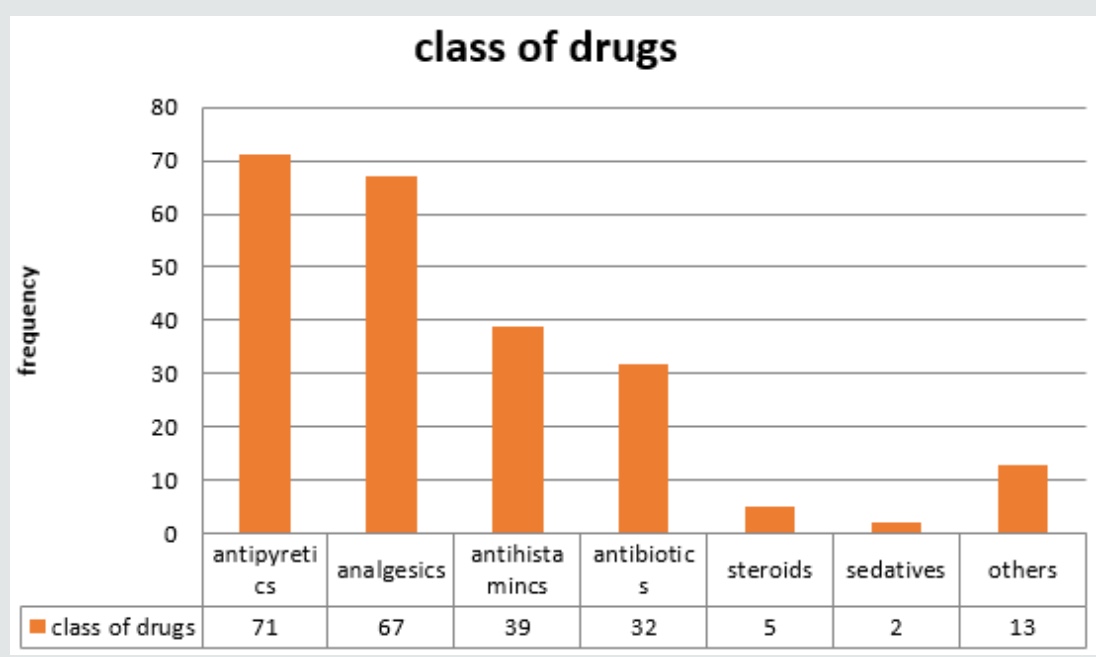

Figure 2: Class of drugs for self-medication.

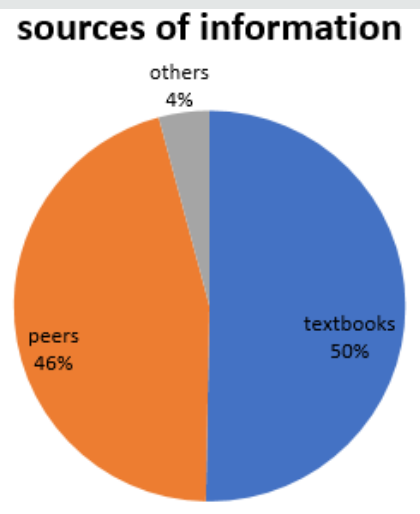

Figure 3: Common sources of information for self-medication. 


\section{References}

1. Badiger S, Kundapur R, Jain A, Kumar A, Patanashetty S, et al. (2012) Self-medication patterns among medical students in South India. AMJ 5(4): 217-220.

2. Shankar PR, Partha P, Shenoy N (2002) Self-medication and non- doctor prescription practices in Pokhara valley, Western Nepal: a questionnaire based study. BMC Fam Pract 3: 17.

3. Montastruc JL, Bagheri H, Geraud T, Lapeyre Mestre M (1997) Pharmacovigilance of self-medication. Therapie 52(2): 105-110.

4. James H, Handu SS, Khalid AJ, Khaja A, Otoom S, et al. (2006) Evaluation of the knowledge, attitude and practice of self-medication among firstyear medical students. Med Princ Pract 15(4): 270-275.

\section{(c) (i) This work is licensed under Creative}

To Submit Your Article Click Here: Submit Article

DOI: $10.32474 /$ SJPBS.2018.01.000125
5. Hughes CM, McElnay JC, Fleming GF (2001) Benefits and risks of selfmedication. Drug Saf 24(14): 1027-1037.

6. Hem E, Stokke G, Reidar Tyssen R, Grønvold NT, Vaglum P, et al. (2005) Self-prescribing among young Norwegian doctors: a nine-year follow-up study of a nationwide sample. BMC Med 3: 16.

7. Kiyingi KS, Lauwo JAK (1993) Drugs in home: danger and waste. World Health Forum 14(4): 381-384.

8. Sarahroodi S, Arzi A, Sawalha AF, Ashtarinezhad A (2010) Antibiotic Self-Medication among South Iranian University Students. International Journal of Pharmacology 6(1): 48-52

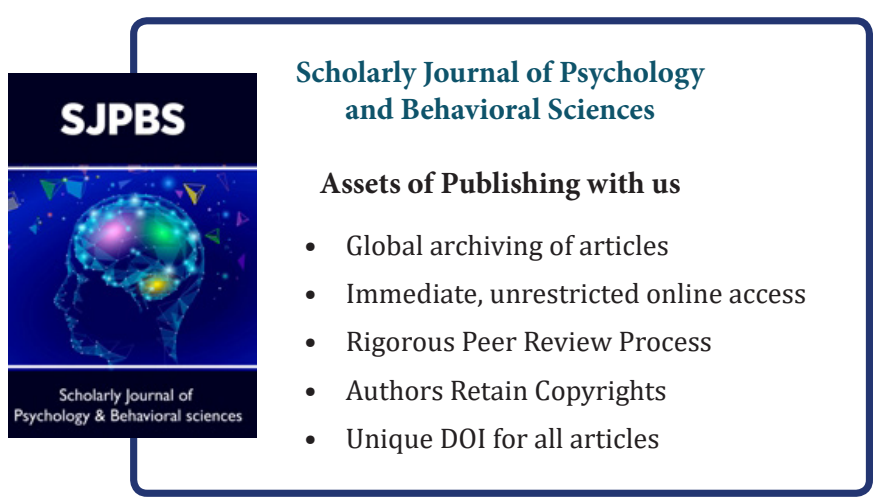

